\title{
LUT
}

University

\section{Power quality estimation of water electrolyzers based on current and voltage measurements}

\author{
Ruuskanen Vesa, Koponen Joonas, Kosonen Antti, Hehemann Michael, Keller \\ Roger, Niemelä Markku, Ahola Jero
}

This is a Author's accepted manuscript (AAM) version of a publication

published by Elsevier

in Journal of Power Sources

DOI: $10.1016 /$ j.jpowsour.2019.227603

Copyright of the original publication: () 2019 Elsevier B.V.

Please cite the publication as follows:

Ruuskanen, V., Koponen, J., Kosonen, A., Hehemann, M., Keller, R., Niemelä, M., Ahola, J. (2020). Power quality estimation of water electrolyzers based on current and voltage measurements. Journal of Power Sources, vol. 450. DOI: 10.1016/j.jpowsour.2019.227603

This is a parallel published version of an original publication.

This version can differ from the original published article. 


\title{
Power quality estimation of water electrolyzers based on current and voltage measurements
}

\author{
Vesa Ruuskanen ${ }^{\mathrm{a}, *}$, Joonas Koponen ${ }^{\mathrm{a}}$, Antti Kosonen ${ }^{\mathrm{a}}$, Michael \\ Hehemann $^{\mathrm{b}}$, Roger Keller ${ }^{\mathrm{b}}$, Markku Niemelä ${ }^{\mathrm{a}}$, Jero Ahola ${ }^{\mathrm{a}}$ \\ ${ }^{a}$ LUT University, P.O. Box 20, FI-53851, Lappeenranta, Finland \\ ${ }^{b}$ Institut für Energie- und Klimaforschung IEK-3, Forschungszentrum Jülich, Jülich, \\ 52428 Germany
}

\begin{abstract}
The ripple of the supplied direct current has a significant effect on the energy efficiency of the water electrolyzer cell. Hydrogen production is defined by the current mean value, but current harmonics generate additional losses in the electrolyzer cell. However, the direct measurement of the DC current in the kiloampere range may be a challenging task compared with the voltage, which is practically in the range of a few hundreds volts in the electrolyzer stack. The effect of current harmonics on the energy efficiency and the voltage mean and root-mean-square (RMS) values is analyzed analytically based on the measured polarization curve of the PEM electrolyzer cell. The results show that both in the case of a theoretical sinusoidal current ripple and a practical thyristor bridge supply, the voltage mean or RMS values do not give a reliable estimate of the power quality. Instead, the voltage waveform as a function of time or the difference between the current mean and RMS values should be monitored.
\end{abstract}

*Corresponding author, vesa.ruuskanen@lut.fi, tel. +358-50-371-1313 
Keywords: Water electrolysis, Power quality, Specific energy consumption, Voltage and current measurement.

\section{Introduction}

In Power-to-X systems, where electrical energy is converted into other forms of energy, the water electrolyzer stack is the main energy consumer, and hydrogen is the main energy carrier in the end product $[1,2]$. The hydrogen production rate of a water electrolyzer is directly proportional to the mean value of the DC current supplied to the electrodes, and thus, the cost of electricity is typically the main contributor to the cost of electrolytic hydrogen gas. The DC voltage level of MW-scale water electrolyzers is typically $200 \mathrm{~V}-300 \mathrm{~V}$ leading to current levels in the kiloampere range, as stated for example in [3]. Owing to the requirements for high DC currents, the rectifiers in conventional industrial water electrolyzers are typically based on thyristors and diodes generating line frequency harmonics to the supplied voltage and current [4].

These harmonics have been shown to have a significant effect on the specific energy consumption (SEC) of water electrolyzers, as demonstrated in $[4,5]$, where one thyristor-based converter topology was compared with a transistor-based one. The comparison was conducted by analyzing the resulting specific energy consumptions for a $5 \mathrm{~kW}$ alkaline water electrolyzer. A laboratory-scale alkaline water electrolyzer was analyzed in [6], where a steady DC current resulted in a minimized cell efficiency loss. It has been shown that a modern transistor-based rectifier could offer up to a $14 \%$ lower specific energy consumption in the alkaline water electrolyzer stack compared 
with a 6-pulse thyristor rectifier [7]. However, the effect of current ripple on the electrolytic cell lifetime is still a key research question for water electrolyzers, as suggestions that poor power quality might speed up cell degradation are given in the literature $[8,9]$.

As direct measurement of electrical power with high currents in the kiloampere range might be challenging, this paper studies the relation between voltage and current RMS values with the electrolyzer cell power and specific energy consumption. The main contributions of this paper are the following. 1) Analysis of the effect of power quality on the DC voltage and DC current mean and root-mean-square values when the DC current waveform is i) sinusoidal with DC offset and ii) a practical industrial waveform generated by a 6-pulse thyristor rectifier. 2) Recommendation for methods to both identify and quantify the effect of power quality on the specific energy consumption and the voltage and current behavior of electrolytic cells.

This paper is organized as follows. Section 2 describes the voltage-current characteristics of electrolyzer cells and introduces the current waveforms applied in the study. The effect of current AC components on the hydrogen production energy efficiency is studied in Section 3 together with the effect of current harmonic components on the cell voltage. Finally, Section 4 concludes the paper.

\section{Materials and methods}

According to Faraday's law on electrolysis, the molar hydrogen production rate $\left(\mathrm{mol} \mathrm{s}^{-1} \mathrm{~cm}^{-2}\right)$ of a single electrolytic cell is linearly proportional to the current value 


$$
\dot{n}_{\mathrm{H}_{2}}=\eta_{\mathrm{F}} \frac{j_{\text {cell }}}{z F}
$$

where $z$ is the number of moles of electrons transferred in the reaction (for hydrogen, $z=2), F$ is the Faraday constant $\left(9.6485 \times 10^{4} \mathrm{C} \mathrm{mol}^{-1}\right), j_{\text {cell }}$ is the current density $\left(\mathrm{A} \mathrm{cm}^{-2}\right)$, and $\eta_{\mathrm{F}}$ is the Faraday efficiency, also known as the current efficiency.

Experimental data are required to model the selected water electrolysis processes as shown in $[10,11,12]$. The electrolytic cell voltage is a sum of the reversible voltage and additional overvoltages occurring in the electrolytic cell

$$
U_{\text {cell }}=U_{\text {ocv }}+U_{\text {ohm }}+U_{\text {act }}+U_{\text {con }}
$$

where $U_{\text {cell }}$ is the cell voltage, $U_{\text {ocv }}$ is the open circuit voltage, which is the lowest voltage required for the water decomposition to occur, $U_{\mathrm{ohm}}$ is the overvoltage caused by ohmic losses in the cell elements, $U_{\text {act }}$ is the activation overvoltage produced by electrode kinetics, and $U_{\text {con }}$ is the concentration overvoltage resulting from mass transport processes [13]. The concentration overvoltage is neglected in this study as the current densities in PEM cells are typically not high enough to meet significant mass-transport limitations [14]. The open-circuit voltage can be described using the Nernst equation

$$
U_{\mathrm{ocv}}=U_{\mathrm{rev}}^{0}+\frac{R T_{\mathrm{el}}}{z F} \ln \left(\frac{p_{\mathrm{H}_{2}} \cdot p_{\mathrm{O}_{2}}^{1 / 2}}{p_{\mathrm{H}_{2} \mathrm{O}}}\right),
$$

where $U_{\mathrm{rev}}^{0}$ is the reversible cell voltage, $R$ is the universal gas constant 
(8.314 $4621 \mathrm{~J} \mathrm{~mol}^{-1} \mathrm{~K}^{-1}$ ), and $T_{\text {el }}$ is the cell temperature. Further, $p_{\mathrm{H}_{2}}, p_{\mathrm{O}_{2}}$, and $p_{\mathrm{H}_{2} \mathrm{O}}$ are the hydrogen, oxygen, and water partial pressures, respectively.

The reversible cell voltage is defined as a function of temperature; for example, for a PEM electrolyzer cell in [16] and for an alkaline electrolyzer cell with the $\mathrm{KOH}$ electrolyte in [17]. However, in this simplified case, the open-circuit cell voltage under constant operating temperature and pressure is considered one parameter to be found by curve fitting of the measured data.

The ohmic overpotential is caused by the voltage across the membrane electrode assembly (MEA) and current collectors, and can be expressed as

$$
U_{\text {ohm }}=R_{\text {cell }} j_{\text {cell }}
$$

where $R_{\text {cell }}$ is the total electrical resistance of the cell.

The activation overpotential is often described by using the Butler-Volmer equation [18]

$$
U_{\text {act }}=\frac{R T_{\text {el }}}{\alpha_{\text {an }} F} \operatorname{arcsinh}\left(\frac{j_{\text {cell }}}{2 j_{\mathrm{o}, \text { an }}}\right)+\frac{R T_{\mathrm{el}}}{\alpha_{\text {cat }} F} \operatorname{arcsinh}\left(\frac{j_{\text {cell }}}{2 j_{\mathrm{o}, \text { cat }}}\right),
$$

where $\alpha$ is the charge transfer coefficient for the anode and the cathode separately, and $j_{\mathrm{o}}$ is the exchange current density on the electrode surfaces. The charge transfer coefficients and the exchange current densities are experimentally defined as a function of temperature for example in [19].

Finally, the simplified model for the cell voltage under constant temperature and pressure as a function of current density can be expressed as

$$
U_{\text {cell }}=U_{\text {ocv }}+R_{\text {cell }} j_{\text {cell }}+\alpha \operatorname{arcsinh}\left(\frac{j_{\text {cell }}}{2 j_{0}}\right),
$$


where $U_{\text {ocv }}, R_{\text {cell }}, \alpha$, and $j_{0}$ are the parameters to be fitted by experimental data.

As the above-mentioned parameters have been found by a measured voltage-current characteristics curve of the electrolyzer cell, the voltage components can be studied separately. According to (3), reversible voltage can be assumed constant as it is not a function of cell current density.

The measured voltage-current characteristics of the studied PEM cell at ambient pressure and temperature of $75^{\circ} \mathrm{C}$ are shown in Fig. 1a. A more detailed description of the experimental setup can be found in [20]. The ohmic and activation overpotentials are shown as a function of current density in Fig. 1b. The linear voltage--current characteristics at highest current densities support neglecting concentration overvoltage in this study, even though the momentarily current density can reach high values in practical devices with high DC current level and AC ripple components.

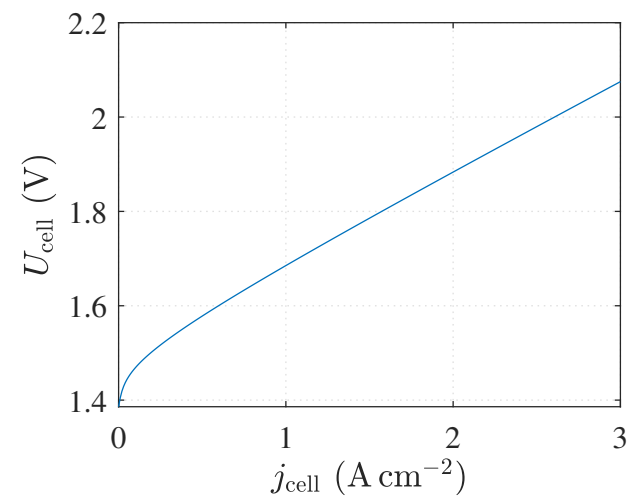

(a)

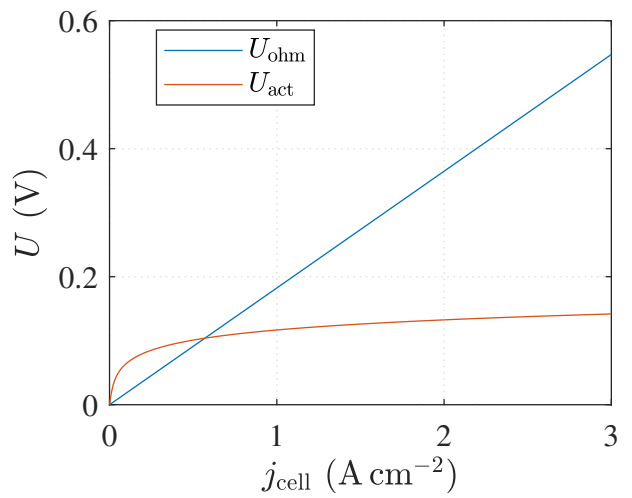

(b)

Fig. 1. Voltage-current characteristics of an example electrolyzer cell; (a) cell voltage, (b) ohmic and activation overpotentials. 
This study assumes, that the power quality effects can be studied based on the voltage-current characteristics measured under static conditions as no significant phase shift between voltage and current was seen even at $1 \mathrm{kHz}$ sinusoidal current ripple in case of an alkaline electrolyzer [21]. It is assumed that high frequency current ripple does not cause pressure or thermal variation as their time constants are significantly longer. Obviously, the additional heating power by the current ripple induced losses needs to taken into account in selection of the temperature of the voltage-current characteristics curve. The specific energy consumption $E_{\mathrm{s}}$ of an electrolysis process can be obtained based on the cell voltage, current density, and hydrogen production rate

$$
E_{\mathrm{s}}=\frac{\int_{0}^{T} P_{\mathrm{A}, \text { cell }} \mathrm{d} t}{\int_{0}^{T} \dot{m}_{\mathrm{H}_{2}} \mathrm{~d} t}=\frac{\int_{0}^{T} j_{\text {cell }} U_{\text {cell }} \mathrm{d} t}{\int_{0}^{T} \dot{m}_{\mathrm{H}_{2}} \mathrm{~d} t},
$$

where $T$ is the time interval under study, $P_{\mathrm{A} \text {, cell }}$ is the area power density of the cell as a function of time, and $\dot{m}_{\mathrm{H}_{2}}$ is the hydrogen gas mass flow rate. The higher heating value (HHV) is the minimum energy required to produce hydrogen gas with a thermoneutral process. The per mass unit HHV of hydrogen gas is $39.4 \mathrm{kWh} \mathrm{kg}^{-1}$, which can be assumed to represent the energy consumption of the process with a $100 \%$ efficiency.

\subsection{Current ripple}

Current or voltage ripple means that there is an alternating current (AC) component in addition to the desired direct current (DC). In this paper, a sinusoidal ripple is used and $i_{\mathrm{AC}}$ defines the ripple amplitude in absolute or per unit values. 1 p.u. means that the AC ripple amplitude equals the DC 
value, and the current density momentarily reaches a zero value, which is illustrated, in addition to root-mean-square (RMS) and peak-to-peak values, in Fig. 2a. AC current amplitudes higher than 1 p.u. are not studied as those would require momentarily negative current, which practically never exists in water electrolyzers. The sinusoidal AC component does not affect the mean value of the current, and thus, $j_{\text {mean }}=j_{\text {DC }}$. Fig. $2 \mathrm{~b}$ illustrates the difference between current RMS and mean values.

Because of the nonlinear cell polarization curve, the voltage ripple, in Fig. 2c, is not purely sinusoidal despite the sinusoidal current ripple. Therefore, $U_{\text {mean }}$ and $U_{\mathrm{RMS}}$ refer to the mean and RMS values of the actual voltage waveform $U_{\text {cell }}$. $U_{\mathrm{DC}}$ refers to the voltage value with a pure DC supply without ripple under an equal hydrogen production rate as Faraday efficiency is neglected. Similarly, in Fig. $2 \mathrm{~d}, P_{\mathrm{A}, \mathrm{DC}}$ refers to the power density with pure DC supply without current ripple as $P_{\mathrm{A} \text {, cell }}$ describes the cell area power density as a function of time. $P_{\mathrm{A} \text {, mean }}$ is simply cell power density mean value over time, and simply called cell power later on. Further, in the case of electrical supply power, 1 p.u. refers to the power required to produce an equal amount of hydrogen with a pure DC supply $P_{\mathrm{A}, \mathrm{DC}}$.

The RMS values are widely used in electrical engineering. The RMS value of a varying voltage or current equals the $\mathrm{DC}$ value, which gives the same power dissipated by an electrical resistance. The RMS value of current, or current density in this case, is defined as an integral over the periodic time

$$
j_{\mathrm{RMS}}=\sqrt{\frac{1}{T} \int_{0}^{T} j_{\text {cell }}^{2} \mathrm{~d} t},
$$

where $T$ is the periodic time of the cell current. For voltage, the RMS values 


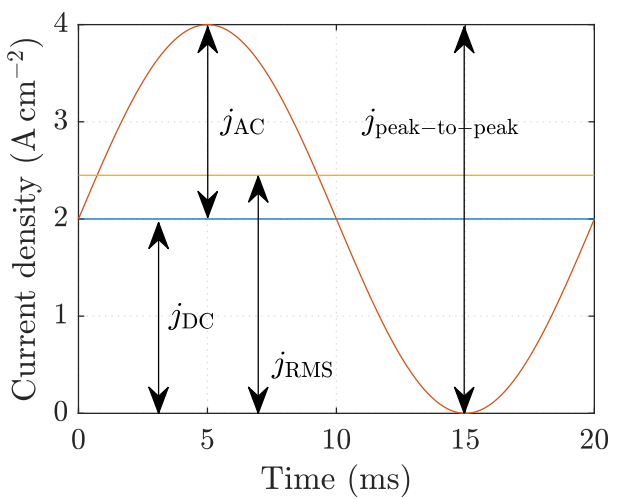

(a)

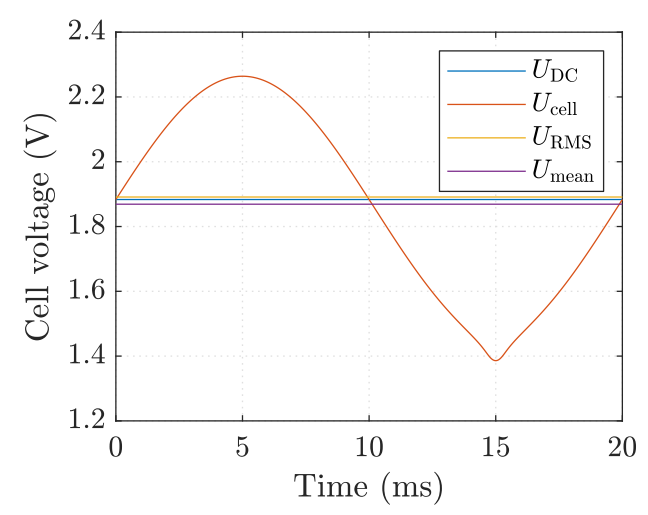

(c)

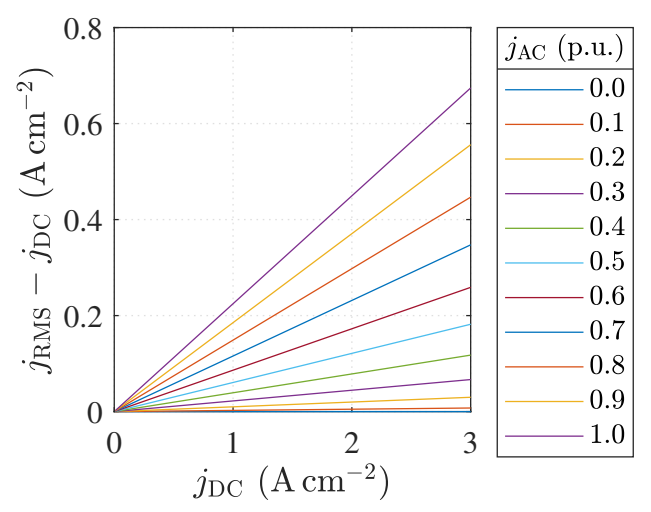

(b)

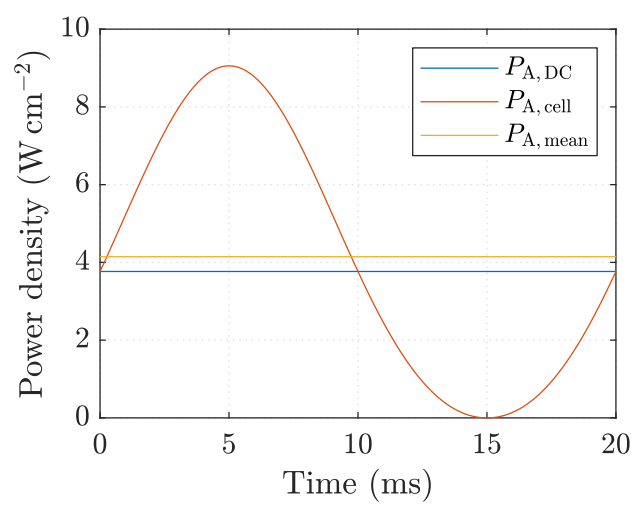

(d)

Fig. 2. Current ripple illustration; (a) 1 p.u. sine current ripple $\left(j_{\mathrm{AC}}=j_{\mathrm{DC}}\right)$ with the example DC current density level of $2 \mathrm{~A} \mathrm{~cm}^{-1}$ together with respective RMS and peakto-peak values, (b) difference of the current mean and RMS values as a function of ripple amplitude, (c) cell voltage calculated based on current DC value, as a function of time, voltage RMS, and mean values, (d) cell area power density calculated in case of pure DC supply, with current ripple as a function of time, and the mean value of power density with ripple.

are defined similarly as in the case of current. In the case of sinusoidal ripple, the current RMS value can be given based on DC and AC component 
amplitudes

$$
j_{\mathrm{RMS}}=\sqrt{j_{\mathrm{DC}}^{2}+\left[\frac{1}{\sqrt{2}} j_{\mathrm{AC}}\right]^{2}} .
$$

Therefore, the current ripple increases the RMS value of the current as shown in Fig. 2b. Most AC circuits can roughly be assumed to have a sinusoidal waveform with no DC component. Therefore, some low-end measurement devices estimate the RMS value directly by the peak value of the current, which equals to the $\mathrm{AC}$ component in case of pure $\mathrm{AC}$ current without $\mathrm{DC}$

component, $j_{\mathrm{RMS}}=\frac{1}{\sqrt{2}} j_{\mathrm{AC}}$. Typically, the measurement devices also give the peak-to-peak value, which is the difference between the minimum and maximum values of the signal, or the minimum and maximum values separately. On the other hand, even if the waveforms are measured point-by-point, it is essential to calculate both the mean and RMS values. The situation is the same if the values are measured by power analyzers (without knowing the waveform), and thus, the mean and RMS values should be checked. Therefore, the experimental analysis of power quality and its impact on the specific energy consumption of an electrolytic cell requires knowledge on the electrical measurement devices in question and the methodology to determine the electrical quantities.

\section{Results and discussion}

This section first introduces and discusses the effect of sinusoidal current ripple on the key electrical and energy consumption characteristics of the electrolytic cell. Finally, the key characteristics are analyzed in the case of a practical industrial 6-pulse thyristor rectifier. 
3.1. Effect of current ripple on the electrical power and specific energy consumption

The electrical supply power area density of the electrolytic cell can be defined by cell voltage and current as shown in the numerator of (7). The effect of current ripple on the supply power is studied in Fig. 3, where the power with current ripple is compared with the power with pure DC current.

It is clearly seen that the current ripple increases the required supply power. The power consumed by the ohmic and activation overpotentials is shown in Fig. 3c and Fig. 3d. As the ohmic overpotential is linearly related to the current, based on the definition of RMS values ohmic loss is linearly dependent on the square of RMS current. Further, in case of sinusoidal ripple, p.u. value of the resistive loss power density can be written based on

$$
P_{\mathrm{A}, \text { ohm }}=\frac{j_{\mathrm{RMS}} U_{\mathrm{RMS}}}{j_{\mathrm{DC}} U_{\mathrm{DC}}}=\frac{R_{\text {cell }} j_{\mathrm{RMS}}^{2}}{R_{\text {cell }} j_{\mathrm{DC}}^{2}}=\frac{R_{\text {cell }} j_{\mathrm{DC}}^{2}+R_{\text {cell }} j_{\mathrm{AC}}^{2}}{R_{\text {cell }} j_{\mathrm{DC}}^{2}}=1+\left[\frac{j_{\mathrm{AC}}}{j_{\mathrm{DC}}}\right]^{2} .
$$

It can be seen that the p.u. value of the resistive loss is not a function of current DC value, but just the relation between current $\mathrm{AC}$ and $\mathrm{DC}$ components. Therefore, the power lines of ohmic losses in Fig. 3c are overlapping. However, the relation of the activation overpotential to the current is not linear, and activation loss is not linearly dependent on the square of current. Therefore, the p.u. value of the activation loss also depends on the current mean value.

According to (1), the hydrogen production is directly proportional to the charge transferred, leading to a linear relation between the hydrogen pro- 


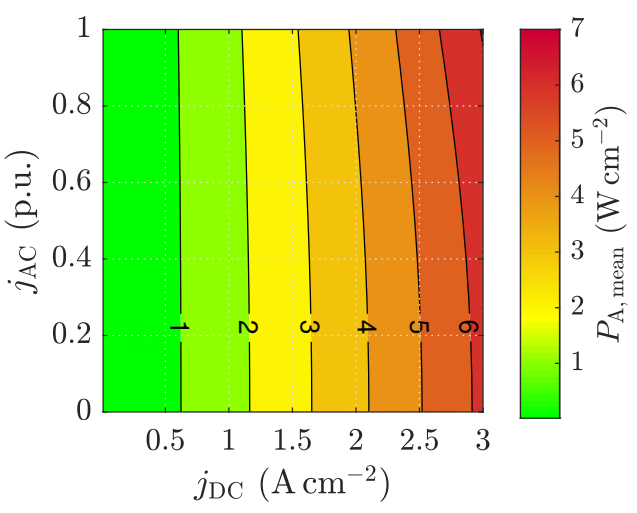

(a)

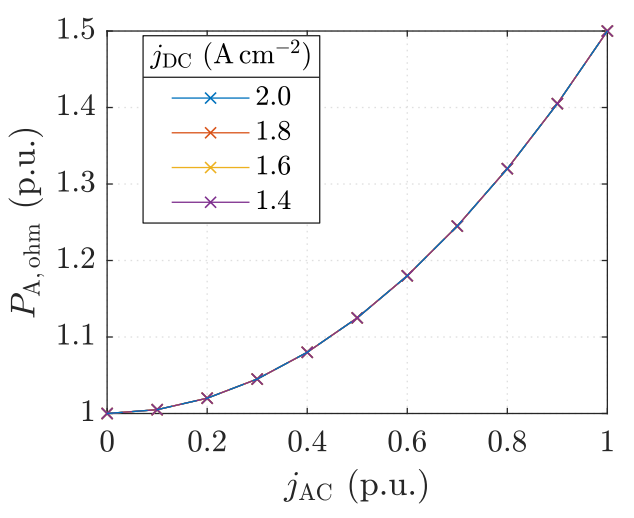

(c)

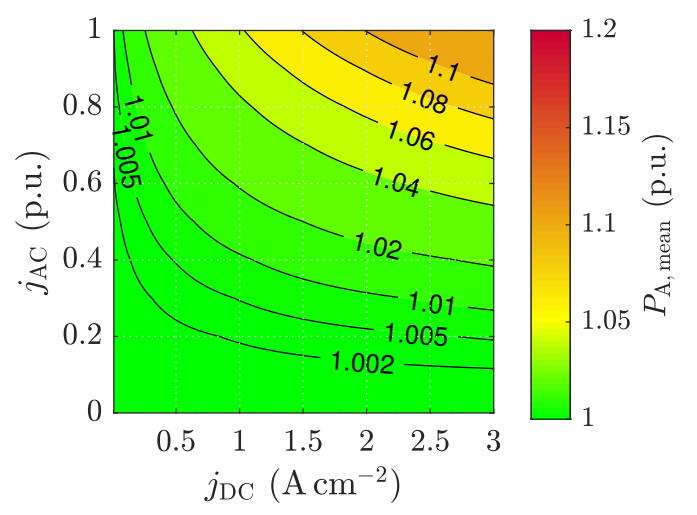

(b)

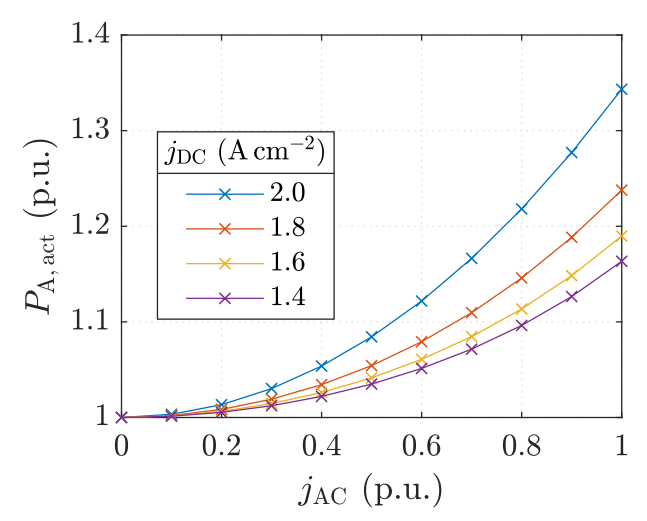

(d)

Fig. 3. Electrical supply power of the cell as a function of current AC and DC components; (a) in absolute values, (b) compared with a pure DC supply in per unit values. Loss components compared with a pure DC supply, (c) ohmic loss, (d) activation loss.

duction and the current mean value. As seen in Fig. 4a, the current ripple does not affect the hydrogen production if the Faraday efficiency is assumed constant. However, in practice, the Faraday efficiency behaves nonlinearly and has the lowest values under the lowest current densities because of the leakage currents and gas crossover phenomena [22, 23]. Hence, the hydro- 
gen production may decrease if the ripple decreases the current density low enough at some time.

Finally, the effect of current ripple on the specific energy consumption of the electrolytic cell is shown in Fig. 4b. It can be stated that the current ripple may significantly increase the electrolyzer specific energy consumption, as expected.

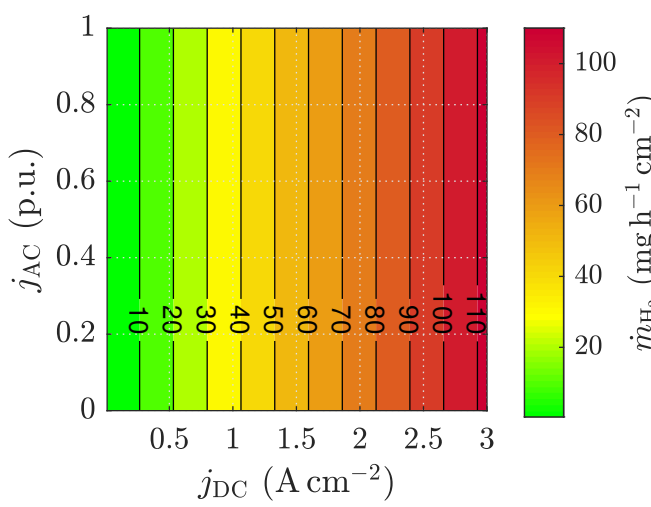

(a)

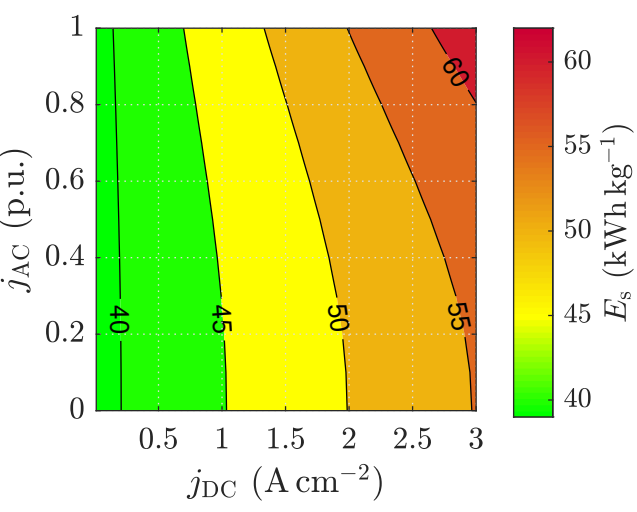

(b)

Fig. 4. Effect of power quality on hydrogen production and specific energy consumption as a function of current $\mathrm{AC}$ and DC components; (a) hydrogen production mass flow rate $\left(\mathrm{mg} \mathrm{h}^{-1} \mathrm{~cm}^{-2}\right)$ as the Faraday efficiency is assumed unity, (b) specific energy consumption $\left(\mathrm{kWh} \mathrm{kg}^{-1}\right)$ of the cell.

\subsection{Effect of current ripple on the voltage mean and RMS values}

As the cell voltage under current ripple is defined as a function of time, mean and RMS values are typically studied. With a resistive load with linear current-voltage characteristics, the mean value of current would be independent and the RMS value would increase as a function of ripple amplitude as in the case of current. However, the nonlinear activation overpotential 
leads to a fact that the voltage mean value is actually slightly decreased as a function of current ripple as shown in Fig. 5.

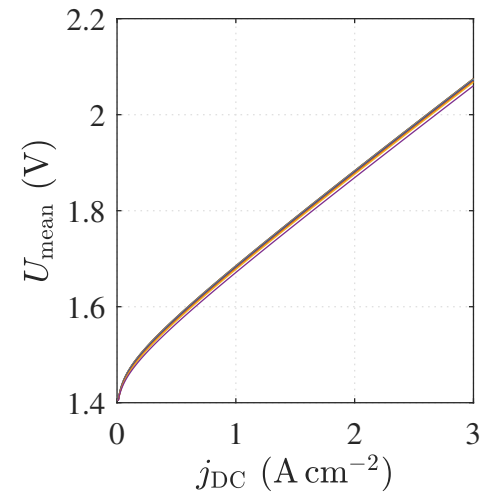

(a)

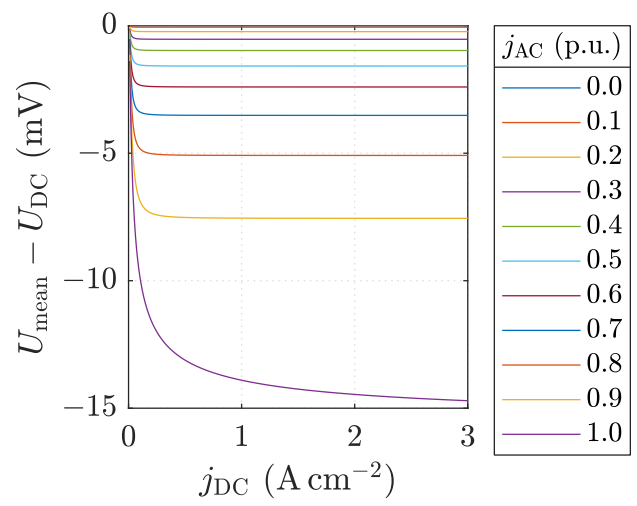

(b)

Fig. 5. Cell voltage mean value as a function of current DC and AC components; (a) cell voltage mean value, (b) difference in the cell voltage mean value compared with the cell voltage with pure DC.

The voltage RMS value is analyzed in Fig. 6a and Fig. 6b. There is no clear trend in the voltage RMS value as a function of current ripple. The nonlinear activation overpotential tends to decrease the RMS value especially at lower current densities as the linear ohmic overpotential increases the voltage RMS value at higher currents. Therefore, the voltage RMS value with ripple gets lower values than the DC voltage at current densities below $1 \mathrm{~A} \mathrm{~cm}^{-2}$ and higher values than the DC voltage at higher current densities. The cell voltage peak-to-peak value behaves nonlinearly as a function of current components as shown in Fig. 6c. 


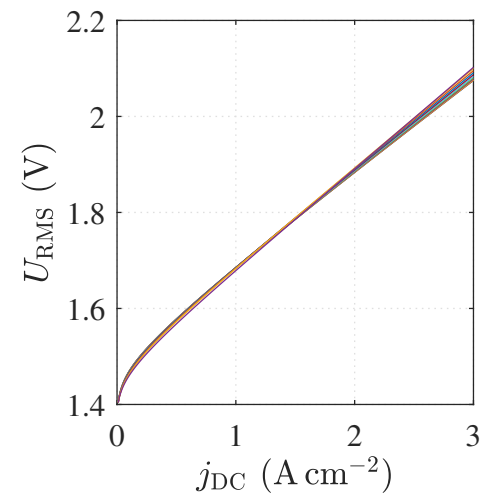

(a)

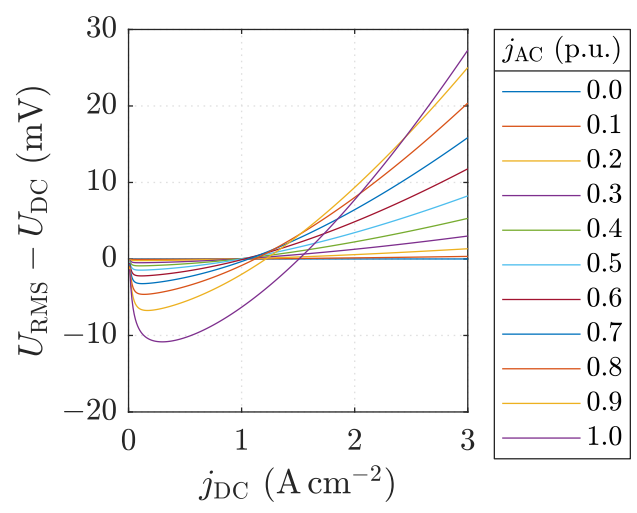

(b)

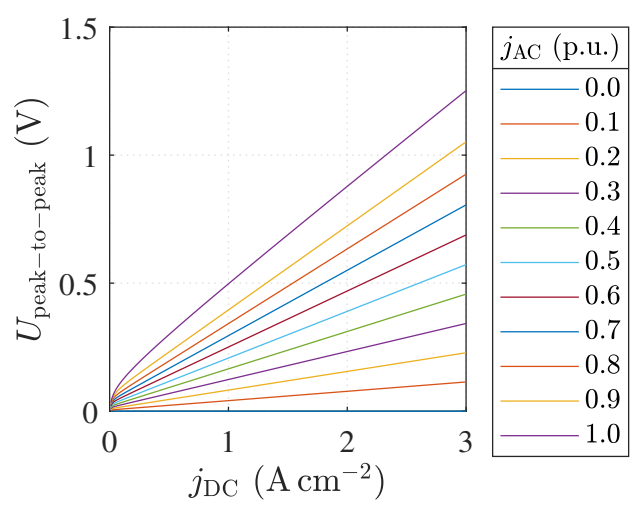

(c)

Fig. 6. Cell voltage RMS and peak-to-peak values as a function of current DC and AC components; (a) cell voltage RMS value, (b) difference in the cell voltage RMS value compared with the cell voltage with pure DC, (c) cell voltage peak-to-peak value.

\subsection{6-pulse thyristor bridge}

The thyristor rectifier has been shown to generate high harmonics and thereby decrease the electrolyzer efficiency. The thyristor bridge rectifier was compared with a transistor based on example waveforms in [7]. It was further shown that the grid $\mathrm{AC}$ voltage level has a significant effect on the DC 
power quality of the thyristor rectifiers. Thus, the power consumption of the studied PEM cell as a function of current density under an example constant grid voltage compared with a pure DC supply is shown in Fig. 7a. Further, the peak-to-peak values of cell current density and voltage are illustrated as a function of current density in Fig. 7b. Fig. 7c shows two current waveforms as a function of time around the current DC value where the current starts to momentarily reach zero, which is seen as a knee point in the voltage and current peak-to-peak value curves.

The harmonics generated by the thyristor bridge induce significant additional losses even in the PEM cell with a relatively low resistance. The effect of harmonics is emphasized under the lowest current densities, where a large firing angle of the thyristors is required. Especially, the peak-to-peak value of the current is multiple compared with the current mean value. The current and voltage RMS values with a 6-pulse thyristor bridge are shown in Fig. 8.

Because of the large firing angles, the current RMS value is more than $50 \%$ higher than the mean value at low current densities. However, the voltage mean and RMS values are even lower compared with the pure DC supply at the lowest current densities with a high harmonics content. Similarly to the sinusoidal supply, the voltage mean or RMS value does not give any reliable indication of the power quality of the electrolytic cell supplied with a thyristor bridge.

To sum up, current ripple in the DC supply for an electrolytic cell may have significant effect on the specific energy consumption of the electrolytic cell. To identify and quantify the losses in an electrolytic cell, cell voltage is 


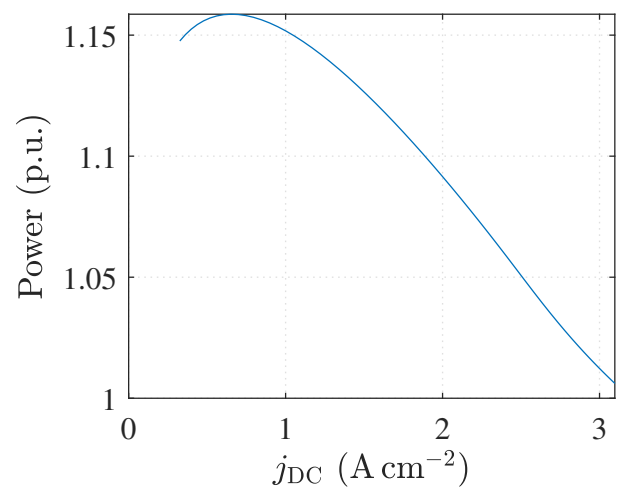

(a)

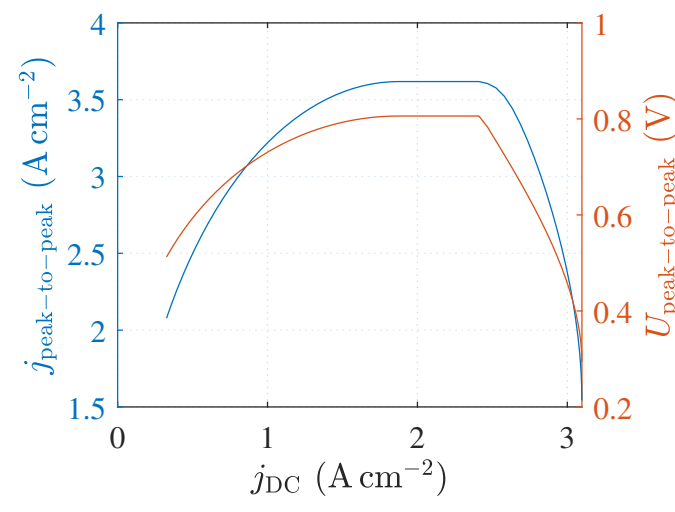

(b)

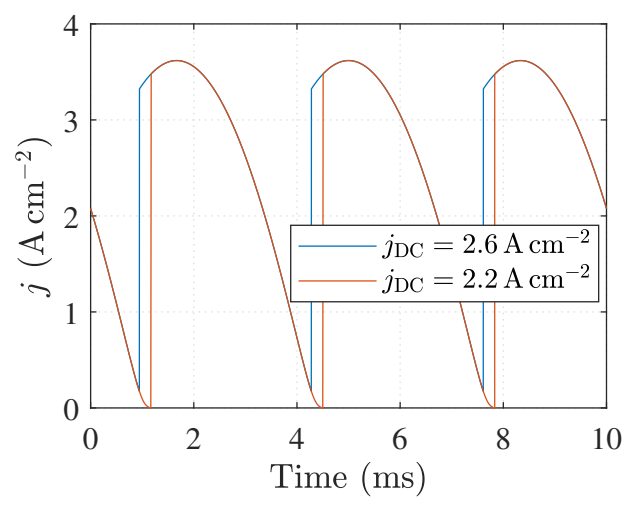

(c)

Fig. 7. 6-pulse thyristor rectifier; (a) electrical supply power (p.u.) of the cell as a function of current density, (b) cell current and voltage peak-to-peak values, (c) example of current waveforms as a function of time.

typically studied. Due to the nonlinear behaviour of electrolytic cell voltage at low current densities, and contrary to a case of a purely resistive load, the mean cell voltage actually slightly decreases as a function of current ripple. The cell voltage RMS value as a function of current ripple is affected by the dominating - nonlinear or linear-loss region of the electrolytic cell, and therefore the cell voltage RMS or the cell voltage mean value are not 


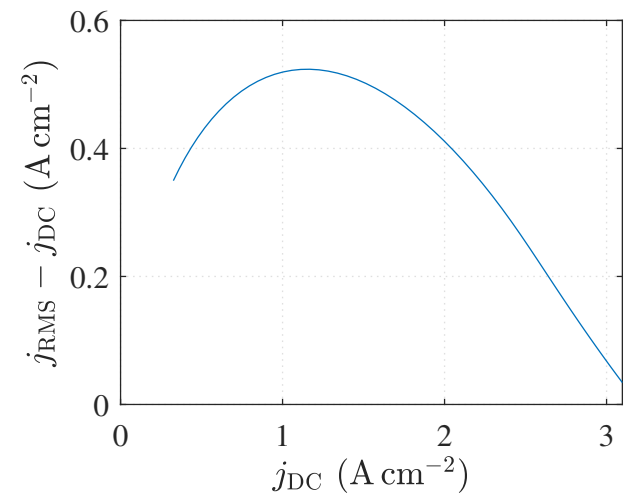

(a)

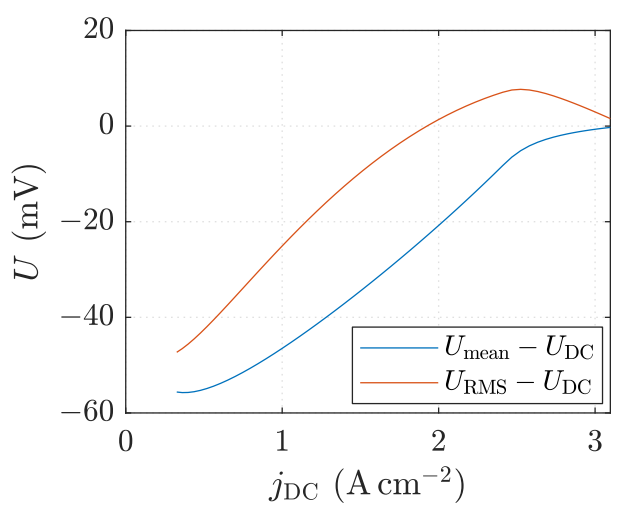

(b)

Fig. 8. Cell current and voltage as a function of current mean value with a 6-pulse thyristor bridge; (a) difference in the current RMS value and mean value, (b) cell voltage mean and RMS values compared with the cell voltage with pure DC.

reliable indicators of power quality. For practical rectifier topologies of water electrolyzer systems, where accurate electric current measurement may be difficult, the cell voltage waveform should be defined point-by-point, and the power quality should be analyzed based on the current-voltage characteristics or the cell equivalent model.

\section{Conclusions}

The electrolyzer cell behavior with sinusoidal current ripple was studied based on the measured voltage-current characteristics. It can be stated that current ripple causes additional losses on the electrolyzer cell. Further, it was found that the difference between the current mean and RMS values indicates additional losses, although an estimate of the actual additional loss power cannot be given based on the current alone. Finally, it was found that no 
direct conclusion on the power quality can be made, although any difference, positive or negative, between the mean and RMS values is an indication of current ripple. To get a reliable estimate of the DC power quality of the water electrolyzers, the measurement of current and voltage waveforms as a function of time is, of course, preferred, but a comparison of the current mean and RMS values gives a good indication of the power quality. This is essential in industrial-scale electrolyzers, in which currents are in the kiloampere range, and therefore, difficult to measure in practice. If only the voltage is measured, it is necessary to define the voltage point-by-point to carry out an estimation based on the known current-voltage characteristics or the cell equivalent model. The future work should not concentrate only on the effect of power quality on the specific energy consumption of water electrolyzers, but the effect of power quality on the cell degradation should be thoroughly considered as well. 


\section{References}

[1] P. Schmidt, W. Zittel, W. Weindorf, T. Raksha, Renewables in Transport 2050 Empowering a sustainable mobility future with zero Final Report, Tech. rep., FVV (2016).

[2] F. Vidal Vázquez, J. Koponen, V. Ruuskanen, C. Bajamundi, A. Kosonen, P. Simell, J. Ahola, C. Frilund, J. Elfving, M. Reinikainen, N. Heikkinen, J. Kauppinen, P. Piermartini, Power-to-X Technology Using Renewable Electricity and Carbon Dioxide from Ambient Air: SOLETAIR Proof-of-Concept and Improved Process Concept, J. $\mathrm{CO}_{2}$ Util. 28 (2018) 235-246.

[3] J. Solanki, N. Fröhleke, J. Böcker, P. Wallmeier, Analysis , Design and Control of 1MW , High Power Factor and High Current Rectifier System, in: Proc. IEEE Energy Conversion Congress and Exposition (ECCE 12), Raleigh, USA, 2012, pp. 1725-1732.

[4] A. Ursúa, P. Sanchis, L. Marroyo, Chapter 14 - electric conditioning and efficiency of hydrogen production systems and their integration with renewable energies, in: L. Gandía, G. Arzamendi, P. Diéguez (Eds.), Renewable Hydrogen Technologies, Elsevier, Amsterdam, 2013, pp. 333360.

[5] A. Ursúa, L. Marroyo, E. Gubía, L. M. Gandía, P. M. Diéguez, P. Sanchis, Influence of the power supply on the energy efficiency of an alkaline water electrolyser, Int. J. Hydrogen Energy 34 (8) (2009) 3221-3233. 
[6] Z. Dobó, Árpád Bence Palotás, Impact of the current fluctuation on the efficiency of alkaline water electrolysis, Int. J. Hydrogen Energy 42 (9) (2017) 5649-5656.

[7] J. Koponen, V. Ruuskanen, A. Kosonen, M. Niemelä, J. Ahola, Effect of Converter Topology on the Specific Energy Consumption of Alkaline Water Electrolyzers, IEEE Trans. Power Electron. 34 (7) (2019) 61716182.

[8] L. Bertuccioli, A. Chan, D. Hart, F. Lehner, B. Madden, E. Standen, Study on development of water electrolysis in the EU, Final report in fuel cells and hydrogen joint undertaking, 2014.

[9] C. Rakousky, U. Reimer, K. Wippermann, S. Kuhri, M. Carmo, W. Lueke, D. Stolten, Polymer electrolyte membrane water electrolysis: Restraining degradation in the presence of fluctuating power, J. Power Sources 342 (2017) 38-47.

[10] A. Ursúa, I. S. Martín, P. Sanchis, Design of a programmable power supply to study the performance of an alkaline electrolyser under different operating conditions, in: 2nd IEEE Int. Energy Conf. and Exhibition (ENERGYCON '12), Florence, Italy, 2012, pp. 259-264.

[11] J. van der Merwe, K. Uren, G. van Schoor, D. Bessarabov, A study of the loss characteristics of a single cell PEM electrolyser for pure hydrogen production, in: Proc. IEEE Int. Conf. Ind. Technol. (ICIT '13), Cape Town, South Africa, 2013, pp. 668-672. 
[12] F. da Costa Lopes, E. H. Watanabe, Experimental and theoretical development of a PEM electrolyzer model applied to energy storage systems, in: Proc. Brazilian Power Electron. Conf. (COBEP ‘09), Bonito-Mato Grosso do Sul, Brazil, 2009, pp. 775-782.

[13] A. Ursúa, P. Sanchis, Static-dynamic modelling of the electrical behaviour of a commercial advanced alkaline water electrolyser, Int. J. Hydrogen Energy 37 (24) (2012) 18598-18614.

[14] R. García-Valverde, N. Espinosa, A. Urbina, Simple PEM water electrolyser model and experimental validation, Int. J. Hydrogen Energy 37 (2) (2012) 1927-1938.

[15] A. Awasthi, K. Scott, S. Basu, Dynamic modeling and simulation of a proton exchange membrane electrolyzer for hydrogen production, Int. J. Hydrogen Energy 36 (22) (2011) 14779-14786.

[16] K. Harrison, E. Hernándec-Pacheco, M. Mann, H. Salehfar, Semiempirical model for determining PEM electrolyzer stack characteristics, J. Fuel Cell Sci. Technol. 3 (2) (2005) 220-223.

[17] R. LeRoy, C. Bowen, D. LeRoy, The thermodynamics of aqueous water electrolysis, J. Electrochem. Soc. 127 (9) (1980) 1954-1962.

[18] J. Larminie, A. Dicks, Fuel cell systems explained, John Wiley \& Sons Ltd., England, 2003.

[19] C. Biaku, N. Dale, M. Mann, H. Salehfar, A. Peters, T. Han, A semiempirical study of the temperature dependence of the anode charge transfer 
coefficient of a $6 \mathrm{~kW}$ PEM electrolyzer, Int. J. Hydrogen Energy 33 (16) (2008) 4247-4254.

[20] M. Schalenbach, Proton Conduction and Gas Permeation through Polymer Electrolyte Membranes during Water Electrolysis, Jülich: Forschungszentrum, Zentralbibliothek, 2018.

URL http://juser.fz-juelich.de/record/850279/files/

Energie_Umwelt_426.pdf

[21] V. Ruuskanen, J. Koponen, T. Sillanpää, A. Kosonen, M. Niemelä, J. Ahola, Considering the Power Quality in the Power-Hardware-in-Loop simulation of the water electrolyzers, in: Proc. 19th European Conf. on Power Electron. and Applicat. (EPE '17-ECCE Europe), Warsaw, Poland, 2017, pp. 1-9. doi:10.23919/EPE17ECCEEurope.2017.8098943.

[22] Ø. Ulleberg, Modeling of advanced alkaline electrolyzers: a system simulation approach, Int. J. Hydrogen Energy 28 (1) (2003) 21-33.

[23] P. Trinke, P. Haug, J. Brauns, B. Bensmann, R. Hanke-Rauschenbach, T. Turek, Hydrogen Crossover in PEM and Alkaline Water Electrolysis: Mechanisms, Direct Comparison and Mitigation Strategies, J. Electrochem. Soc. 165 (7) (2018) F502-F513. 